\title{
The functional role of planktonic mixotrophs in altering seston stoichiometry
}

\author{
Stefanie D. Moorthi ${ }^{1, *}$, Robert Ptacnik ${ }^{2}$, Robert W. Sanders ${ }^{3}$, \\ Robert Fischer ${ }^{1}$, Michaela Busch ${ }^{1}$, Helmut Hillebrand ${ }^{1}$ \\ ${ }^{1}$ Institute for Chemistry and Biology of the Marine Environment (ICBM), University of Oldenburg, Schleusenstraße 1, \\ 26382 Wilhelmshaven, Germany \\ ${ }^{2}$ WasserCluster Lunz, Biologische Station GmbH, Dr. Carl Kupelwieser Promenade 5, 3293 Lunz am See, Austria \\ ${ }^{3}$ Temple University, Department of Biology, 1900 N. 12th Street Philadelphia, PA 19122, USA
}

\begin{abstract}
Mixotrophic protists are widespread and relevant primary producers and consumers in planktonic food webs. Given their dual mode of nutrition, mixotrophs face different constraints in allocating resources to cellular structures compared to strict photoautotrophs. However, little is known about their stoichiometric requirements and their flexibility in nutrient content and thus food quality, or how this affects consumer performance and nutrient recycling. In the present study, we tested for systematic differences in elemental composition between photoautotrophic and mixotrophic protists. We compiled intracellular nutrient ratios of mixotrophic and phototrophic species from culture experiments and from 2 lake surveys. Overall, both laboratory and field data indicated that mixotrophy has a stabilizing effect on the nutrient stoichiometry of primary producers under changing nutrient supply. In laboratory experiments, mixotrophs showed a lower variability in intracellular N:P ratios compared to strict phototrophs and were more stable in their elemental composition in response to a gradient of dissolved N:P availability. With increasing contributions of mixotrophic phytoplankton taxa to total lake phytoplankton, both the mean and variance in seston C:P ratios decreased, i.e. communities with higher proportion of mixotrophs overall exhibited more constrained seston stoichiometry. Our results show that mixotrophy may have direct implications for nutrient cycling and secondary production through regulation of seston stoichiometry, buffering stoichiometric constraints for herbivores and enabling a more stable secondary production compared to systems dominated by phototrophic specialists.
\end{abstract}

KEY WORDS: Mixotrophy · Stoichiometry - Nutrients · Food quality · Trophic transfer · Trophic efficiency $\cdot$ Plankton food web

\section{INTRODUCTION}

Mixotrophic planktonic protists, which are able to combine heterotrophic and phototrophic modes of nutrition within a single cell, have increasingly been recognized and documented in aquatic systems in the past decades (e.g. Sanders \& Porter 1988, Caron 2000, Stickney et al. 2000, Unrein et al. 2007, Hartmann et al. 2012). The combination of using photosynthesis and phagotrophic feeding enables mixotrophs to function on multiple trophic

${ }^{*}$ Corresponding author: stefanie.moorthi@uni-oldenburg.de levels within a food web and to use particulate and dissolved nutrient pools, thus augmenting their nutrition in terms of energy, macronutrients and micronutrients including vitamins and trace metals (Sanders et al. 1990, Caron et al. 1993, Maranger et al. 1998, Jones 2000). These advantages may lend mixotrophs a competitive advantage over strict phototrophs and heterotrophs (Bockstahler \& Coats 1993a,b) and seem to outweigh increased metabolic costs of maintaining both modes of nutrition (Raven 1997).

() The authors 2017. Open Access under Creative Commons by Attribution Licence. Use, distribution and reproduction are unrestricted. Authors and original publication must be credited. 
Mixotrophy, here defined as the combination of photosynthetic carbon fixation and phagotrophic feeding, occurs in a variety of marine and freshwater systems and in various phylogenetic groups and size classes, including algal groups such as chrysophytes, dinoflagellates, haptophytes, raphidophytes and cryptophytes (e.g. Sanders 1991, Unrein et al. 2007 , Jeong et al. 2010, Caron 2016). Phagotrophic phytoflagellates in the nanoplankton ( 2 to $20 \mu \mathrm{m}$ ) size class can constitute a substantial fraction of the phytoplankton community and can be major bacterivores, particularly in oligotrophic systems (Zubkov \& Tarran 2008, Hartmann et al. 2012, Unrein et al. 2014). A number of bloom-forming harmful algae such as dinoflagellates, haptophytes and raphidophytes are also able to consume prey organisms, which is assumed to facilitate their dominance and bloom formation in phytoplankton communities (Burkholder et al. 2008).

Recent modeling efforts indicate dramatic increases in cumulative carbon fixation and/or trophic transfer efficiency when mixotrophy is included (Mitra et al. 2016, Ward \& Follows 2016). In spite of the diversity and wide distribution of mixotrophic organisms and their potential contribution to these ecosystem level processes, they have largely been ignored or marginalized by many plankton ecologists, biological oceanographers and modellers (Mitra et al. 2014; but see Caron 2016 and references therein). There are many systems for which the contribution of mixotrophs to community production and thus also their influence on global biogeochemical cycles remain largely unknown. This becomes especially obvious when addressing coupled elemental cycles and stoichiometry, which has been studied almost exclusively using pure photoautotrophs. Depending on the relative availability and algal demand, algae take up different dissolved nutrients such as nitrogen (N) and phosphorus (P) and thus link the cycle of different elements. The stoichiometry of phytoplankton composition is therefore an important component of global and regional biogeochemical models and has received broad attention in the literature (Sterner \& Elser 2002, Hillebrand et al. 2013 and references therein). Microalgae usually show a broad plasticity in elemental composition depending on nutrient supply ratios, as nutrient assimilation and photosynthetic carbon fixation are physiologically separated; fluctuations in resource supplies and their ratios are therefore partly reflected in a phototroph's elemental composition (Ågren 2004, Hillebrand et al. 2013). In contrast, metazoan consumers generally have a more confined stoichiome- try and higher nutrient content compared to phototrophs (Elser et al. 2000, Persson et al. 2010).

The concept of ecological stoichiometry (ES) acknowledges the importance of nutrient imbalances between consumers and their prey, which particularly affect herbivore-phototroph interactions. Altered stoichiometry of primary producers alters food quality for herbivores, which strongly influences trophic interactions and food web dynamics, constraining consumer grazing and growth rates, as well as nutrient recycling (e.g. Sterner \& Elser 2002, Iwabuchi \& Urabe 2012). ES has successfully been applied to explain consumer food uptake rate, assimilation and growth efficiency (Cross et al. 2003, Fagan \& Denno 2004, Frost et al. 2006), competition between consumer species (Hall 2004, Loladze et al. 2004) as well as the effects of consumers on prey nutrient composition (Daufresne \& Loreau 2001, Hillebrand et al. 2009b).

Even though the relevance of phytoplankton stoichiometry for the transfer of matter and energy to higher trophic levels has been recognized and acknowledged in numerous studies, very few studies have addressed the stoichiometry of mixotrophic organisms that are able to pursue alternative production pathways and can supplement their uptake of inorganic dissolved nutrients and photosynthetic carbon fixation by feeding on prey. While fluctuations in dissolved inorganic nutrients strongly affect intracellular C:nutrient ratios in purely photosynthetic organisms, intracellular nutrient concentrations and ratios should be more stable in mixotrophic organisms, since phagotrophic feeding on nutrient rich prey can potentially compensate for inorganic nutrient limitation. In bacterial prey, for instance, concentrations of potentially limiting nutrients are often several orders of magnitude higher compared to the dissolved phase (e.g. Vadstein 2000). Examining the stoichiometry of mixotrophic organisms thus has important implications for plankton food web dynamics and the cycling of matter and energy, especially in the face of anthropogenic nutrient loadings to aquatic systems (Vitousek et al. 1997, Rockström et al. 2009).

Several studies have investigated concentrations of particular nutrients in mixotrophic flagellates, but most of them focused more on the effect of light, temperature and dissolved nutrient conditions on phagotrophic feeding and its contribution to $\mathrm{C}$ and nutrient budgets (Caron et al. 1993, Li et al. 2000, Skovgaard et al. 2000, 2003, Smalley et al. 2003, Carvalho \& Granéli 2010, Simonds et al. 2010, Brutemark \& Granéli 2011, Wilken et al. 2014, Johnson 2015) or on the relationship of internal nutrient concentrations and toxin production in different harmful dinoflagel- 
lates (Johnsen et al. 1999, John \& Flynn 2000, Van de Waal et al. 2013, Pérez Blanco et al. 2015). We are aware of only 2 empirical studies that have specifically addressed the balance of intracellular nutrients in particular mixotrophs and its dependence on environmental factors and potential differences in their nutrient stoichiometry compared to purely phototrophic or heterotrophic organisms. Chrzanowski et al. (2010) investigated the elemental stoichiometry of the mixotrophic flagellate Ochromonas danica in response to varied bacterial resource composition. They found the molar C:N:P composition in O. danica to be variable depending on the C:N:P of the food source, indicating that this flagellate only weakly regulated its element composition compared to a purely heterotrophic species. However, the authors did not consider stoichiometric variation or comparison of the mixotroph to purely phototrophic algae. The first experimental data suggesting that intracellular nutrient concentrations and ratios are more stable (less variable) in mixotrophs compared to pure phototrophs were provided by Katechakis et al. (2005). Their study compared stoichiometry and biomass production of a phototrophic specialist alga (Scenedesmus) and 2 mixotrophic nanoflagellates (Cryptomonas sp. and Ochromonas tuberculata) under different light and $\mathrm{P}$ supply and compared their relative food quality for zooplankton. In accordance with the light:nutrient hypothesis (Sterner et al. 1997), biomass and nutrient stoichiometry of the phototrophic specialist were very variable and strongly depended on light and nutrient supply. Growth and fecundity of the zooplankton consumer Daphnia magna fed with Scenedesmus was limited by food quantity at low light intensities and by food quality (high C:nutrient ratios of prey) at high light intensities. In contrast, biomass and nutrient stoichiometry of the mixotrophs were hardly affected by different nutrient and light supply, as they compensated for light and $\mathrm{P}$ deficiency by feeding on bacteria. O. tuberculata was toxic to D. magna and not considered further by Katechakis et al. (2005), but presence of the mixotroph Cryptomonas resulted in higher and more stable secondary production at most light:nutrient supply ratios compared to the purely phototrophic Scenedesmus. This suggests that mixotrophs indeed may have a balancing effect on food webs under variations of light and dissolved nutrient supply, potentially increasing the energy transfer efficiency to higher trophic levels. Despite its potential relevance for food web dynamics and nutrient cycling in a changing environment, the specific role of mixotrophs for seston stoichiometry has been largely ignored.
In the present study we therefore aimed for a better understanding of mixotroph stoichiometry by comparing intracellular nutrient data (N:P) from laboratory studies on mixotrophic species (nanoflagellates, dinoflagellates and ciliates) growing at different concentrations of dissolved $\mathrm{N}$ and $\mathrm{P}$. We compared this information to equivalent laboratory data from purely photosynthetic organisms across marine and freshwater systems spanning different taxonomic groups (dataset derived from Hillebrand et al. 2013). In addition, we analyzed seston C:P ratios from natural phytoplankton communities as a function of the contribution of potentially mixotrophic species to the total phytoplankton community. We utilized data from 2 lake surveys that were carried out during summer stratification in 2004 (Striebel et al. 2009a, 2009b) and 2012 (Horváth et al. 2017).

We used these data to address 2 hypotheses: (1) purely phototrophic species are more variable in their intracellular N:P ratios than mixotrophic species and show a stronger response to varying dissolved $\mathrm{N}$ :P ratios in the external medium compared to mixotrophic species because mixotrophs are able to compensate for limiting of dissolved nutrients by also exploiting particulate organic nutrient sources, i.e. feeding on prey; and (2) with increasing contribution of potentially mixotrophic species to the total phytoplankton community, seston C:P ratios and the variability of these ratios decrease because mixotrophs are able to buffer inorganic nutrient limitation by phagotrophic feeding on prey.

\section{METHODS}

\section{Laboratory cultures}

For the purely phototrophic species, we used a composite dataset of algal N:P compiled by Hillebrand et al. (2013). This composite dataset includes 56 datasets comprising 590 N:P ratios from 29 publications, including only cyanobacteria and diatoms, i.e. taxonomic groups in which no potential mixotrophs occur, as well as chlorophytes which have few marine and no known freshwater mixotrophs.

For mixotrophic species, we searched the Web of Science by the Institute for Scientific Information for studies reporting intracellular particulate nutrient concentrations. We used the search terms 'mixotroph $^{* \prime}$ and ('nutrient ${ }^{* \prime}$ or 'stoichiometr*'), as well as 'dinoflagellate*' and ('nutrient*' or 'stoichiometr*'). From the studies we found, we included those into our analysis that contained particulate $\mathrm{N}$ and $\mathrm{P}$ data 
of laboratory cultures of mixotrophic species to calculate intracellular N:P ratios. In many cases, a single publication yielded multiple datasets that were included if independent experiments were performed by growing the same mixotrophic species under different conditions (e.g. different nutrient or light conditions (see Figs. S1 \& S2 in the Supplement at www. int-res.com/articles/suppl/a079p235_supp.pdf) or if more than one species were investigated in a single study. In total, we collected $212 \mathrm{~N}$ :P ratios for 17 mixotrophic species from 16 publications and 2 so far unpublished studies, comprising 3 ciliate species, 8 dinoflagellate species, 3 chrysophyte, 2 haptophyte and 1 cryptophyte species (Table 1), feeding on either bacterial or microalgal prey. For our analysis, we pooled all the data from different taxonomic groups, as data were too scarce to distinguish between different groups of mixotrophs. Overall, the studies included were quite inconsistent in the data they provided. Some of them stated intracellular nutrient concentrations of mixotrophs after growing with prey organisms (we excluded studies where particulate nutrient data presented combined results for the stoichiometry of mixotrophs and their prey), while other studies provided data for known mixotrophs without enrichment with specific prey organisms (especially

Table 1. Publications providing data on intracellular N:P ratios in mixotrophic organisms

\begin{tabular}{|c|c|c|}
\hline $\begin{array}{l}\text { Taxonomic } \\
\text { group }\end{array}$ & Species & Publication \\
\hline \multicolumn{3}{|l|}{ Freshwater } \\
\hline Chrysophyte & Dinobryon cylindricum & Caron et al. (1993) \\
\hline Chrysophyte & Ochromonas danica & Chrzanowski et al. (2010) \\
\hline Chrysophyte & Ochromonas danica & Simonds et al. (2010) \\
\hline Chrysophyte & Ochromonas danica & Wilken et al. (2014) \\
\hline Chrysophyte & Ochromonas tuberculata & Katechakis et al. (2005) \\
\hline Cryptophyte & Cryptomonas sp. & Katechakis et al. (2005) \\
\hline Ciliate & Euplotes daidaleos & S. D. Moorthi (unpubl. data) \\
\hline Ciliate & Coleps sp. & S. D. Moorthi (unpubl. data) \\
\hline \multicolumn{3}{|l|}{ Marine } \\
\hline Dinoflagellate & Alexandrium catenella & M. Busch et al. (unpubl. data) \\
\hline Dinoflagellate & Lingulodinium polyedrum & M. Busch et al. (unpubl. data) \\
\hline Dinoflagellate & Alexandrium tamarense & Van de Waal et al. (2013) \\
\hline Dinoflagellate & Ceratium furca & Smalley \& Coats (2002) \\
\hline Dinoflagellate & Ceratium furca & Smalley et al. (2003) \\
\hline Dinoflagellate & Dinophysis norvegica & Gisselson \& Granéli (2001) \\
\hline Dinoflagellate & Fragilidium subglobosum & Skovgaard et al. (2000) \\
\hline Dinoflagellate & Gyrodinium galatheanum & Li et al. (2000) \\
\hline Dinoflagellate & Prorocentrum minimum & M. Johnson (2015) \\
\hline Haptophyte & Chrysochromulina leadbeateri & Johnsen et al. (1999) \\
\hline Haptophyte & Prymnesium parvum & Carvalho \& Granéli (2010) \\
\hline Haptophyte & Prymnesium parvum & Skovgaard et al. (2003) \\
\hline Haptophyte & Prymnesium parvum & Brutemark \& Granéli (2011) \\
\hline Ciliate & Mesodinium rubrum & Brutemark \& Granéli (2011) \\
\hline
\end{tabular}

dinoflagellate studies), and some studies provided both kinds of data. However, none of the mixotrophic cultures were axenic, i.e. all of them contained potential bacterial prey, even if protistan prey was not present. Therefore, we can assume that mixotrophic cultures that were grown without specific prey additions might have ingested bacterial prey and were thus also growing mixotrophically. All of the included laboratory studies provided N:P availability in the medium of the cultures, most of the studies also provided light intensities (see Figs. S1 \& S2); other environmental parameters, however, were provided too inconsistently to be included in our analyses.

We compared the median N:P ratio of purely phototrophic species to that of mixotrophic species across the entire data set, transforming all data to molar N:P ratios. Thereby, we determined the range and variability of N:P ratios for both groups and tested potential differences of the N:P distributions with a Kolmogorov-Smirnov (KS) test. We then analyzed the correlation between the internal N:P ratios to the supplied N:P ratios for phototrophs and mixotrophs respectively. We used a general linear model (glm) with organism identity (mixotroph versus phototroph) as categorical binary variable and ln-transformed $\mathrm{N}: \mathrm{P}$ availability as a continuous variable. A significant interaction $(p<0.05)$ between organism identity and ln-transformed $\mathrm{N}: \mathrm{P}$ availability suggests a significant difference between slopes.

\section{Field data}

We used seston stoichiometry (C:P) data from 2 lake surveys that were carried out in Germany (Bavaria) and Austria in September 2004 (Survey $A_{i}$ Striebel et al. 2009a,b) and August to September 2012 (Survey B $B_{i}$ Horváth et al. 2017). These particular surveys were selected because both studies had reliable microscopic biovolume estimates and used highly comparable methods in terms of sampling procedure etc. (Striebel et al. 2009a,b, Horváth et al. 2017). In these surveys, altogether 76 samples were collected from 61 different lakes in south-eastern Germany and Austria during summer stratification (July to early 
September). Survey A used 42 samples from 36 lakes and Survey B used 34 samples from 34 lakes; 9 lakes were sampled in both surveys. Integrated epilimnetic water samples were taken from boats in both cases. Species were identified and quantified by light microscopy, and species-specific biovolumes were estimated by approximation to simple geometrical bodies. At least 20 cells were measured for each abundant species in each sample. In an initial analysis, we checked whether microscopic estimates of algal biovolume scaled with sestonic particulate organic carbon (POC) (Fig. S3). For details on sampling procedure and microscopic analysis see Striebel et al. (2009a) and Horváth et al. (2017). Particulate fractions of $\mathrm{C}$ and $\mathrm{P}$ were analyzed as outlined in Striebel et al. (2009a). Data from both lake surveys were pooled, and the percentage of mixotrophs was estimated by pooling the biovolume of all taxa with potential phagotrophic capacity (chrysophytes excluding Synurophyta, Cryptophyta, Dinophyta and Haptophyta) and dividing it by the total phytoplankton biovolume. Ciliates and heterotrophic protists (especially heterotrophic dinoflagellates and cryptophytes) were not considered in this analysis. In order to limit the variability of total $\mathrm{P}$ as confounding factor, eutrophic samples (total $\mathrm{P}>30 \mathrm{\mu g} \mathrm{l}^{-1}$ ) were excluded from the analysis. Within the selected data, $\mathrm{C}: \mathrm{P}$ is uncorrelated with total $\mathrm{P}$ (Spearman's $\rho=$ 0.053; Fig. S3).

In order to examine the dependence of seston C:P ratios on mixotrophs, we performed a regression of molar C:P on the proportion of mixotrophs (\% mixotrophs) in the total phytoplankton community for each sample, using generalized additive models for location scale and shape (GAMLSS; Rigby \& Stasinopoulos 2005). Non-constant error variance was fit along with the mean, as the pattern suggested heteroscedasticity along the \% mixotrophs gradient. Model selection was performed by first fitting a minimal model (trend of the mean) and subsequently testing whether the model was significantly improved when taking non-constant error variance into account (AIC criterion). In order to test for the robustness of a trend of C:P with \% mixotrophs, we also calculated a rank correlation.

\section{RESULTS}

\section{Laboratory cultures}

The distributions of molar cellular N:P ratios differed significantly between mixotrophs and photo- trophs (KS test, $D=0.196, \mathrm{p}<0.001$ ). The median molar N:P of phototroph biomass in the laboratory studies examined here was 15.00 (interquartiles from 8.53 to 31.37 ), whereas for mixotrophs the median was slightly higher (19.7) and the interquartiles were less widespread (12.32 to 25.40) (Fig. 1). With increasing N:P of available dissolved nutrients, both mixotrophs and phototrophs increased their internal $\mathrm{N}: \mathrm{P}$ ratios. Both main factors, available $\mathrm{N}: \mathrm{P}$ and organism identity (mixotroph versus phototroph), significantly affected cellular N:P ratios $(\mathrm{p}<0.001$ for both factors), explaining $54 \%$ of the variation in the glm (adjusted $\mathrm{R}^{2}=0.538$ ). Also the interaction of both factors was significant $(p<0.001)$, suggesting a significant difference between the slopes of cellular versus dissolved N:P in ln-ln space (Fig. 2). These data indicate that, as the relative availability of dissolved $P$ decreased (available N:P increased), more P was retained in mixotroph biomass compared to phototroph biomass.

Overall, the range of N:P ratios provided for different groups in different studies was broader for phototrophs than for mixotrophs (Fig. S1), which also might have contributed to more variable N:P ratios in phototrophs. The range of light intensities used in

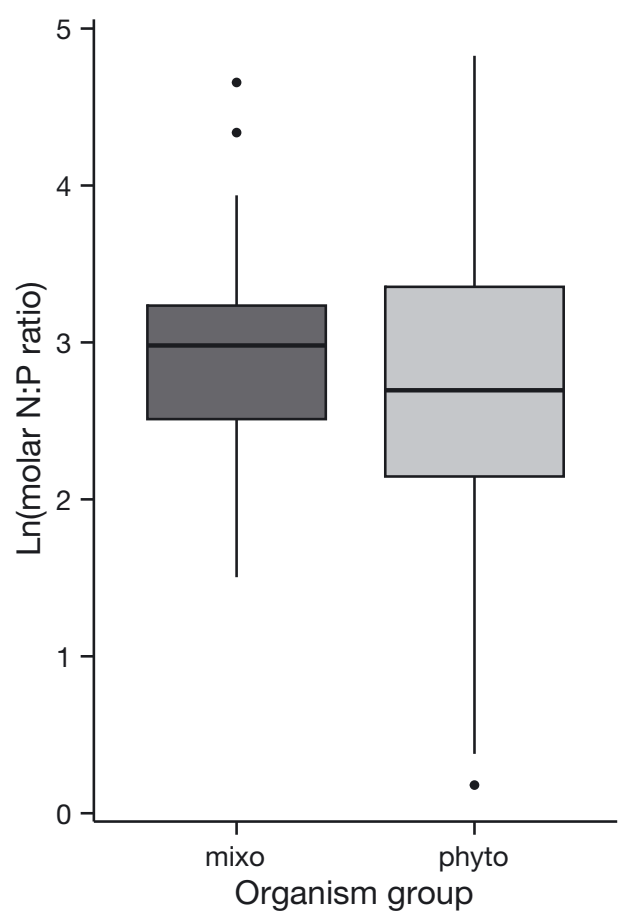

Fig. 1. Molar N:P ratios (ln) of mixotrophic (mixo, $n=212$ ) and strictly photoautotrophic (phyto, $\mathrm{n}=590$ ) planktonic protists, based on data pooled from laboratory studies (Table 1 ; Hillebrand et al. 2013). Median (horizontal line), interquartiles (boxes) and ranges (vertical lines) are shown as well as outliers ( $>1.5$ times interquartile range) 


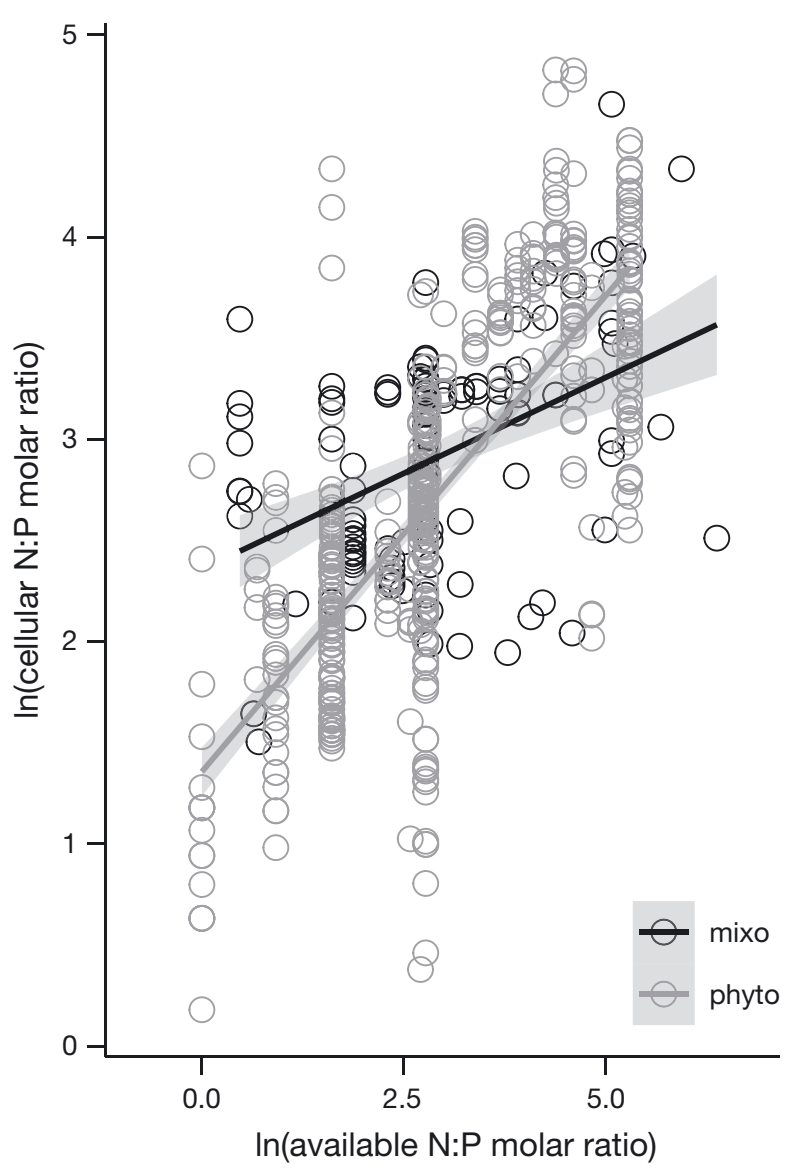

Fig. 2. Molar N:P ratios (ln) of mixotrophic (mixo) and strictly photoautotrophic (phyto) planktonic protists along a gradient of available N:P ratios in the external medium. Lines are linear regressions with the standard error of the slope as shaded area

different studies, however, was much broader for phototrophs than for mixotrophs; we can thus assume that light intensities did not play a role as a biasing parameter confounding the patterns observed in our study (Fig. S2).

\section{Field data}

A negative correlation between proportion of mixotroph biomass in a community and sestonic C:P was evident from a rank correlation (Spearman's $\rho=$ $-0.29, \mathrm{p}=0.01)$. As the data indicated non-constant error variance with increasing fraction of mixotrophs, we fitted a GAMLSS model, which allows fitting trends in mean and error variance simultaneously. Model selection clearly supported a negative relationship between sestonic C:P ratios and the relative contribution of mixotroph biomass to the total phytoplankton community (fraction of mixotrophs; Fig. 3).
Furthermore, variation of this relationship decreased with increasing proportion of mixotrophs on total phytoplankton abundance in the lake surveys: the predictability of seston stoichiometry was higher in samples with high proportion of mixotrophs (heteroscedastic relationship; Fig. 3).

\section{DISCUSSION}

Both laboratory and field data indicated that mixotrophic organisms have a balancing effect on the nutrient stoichiometry of primary producers under changing environmental conditions that potentially alter algal nutrient content and thus food quality. Supporting Hypothesis 1, in laboratory cultures, mixotrophs showed a lower variability in their intracellular N:P ratios compared to strict photoautotrophs and were less responsive to the N:P availability gradient, i.e. showed a less pronounced increase in internal N:P with increasing $\mathrm{N}: \mathrm{P}$ ratios in the external medium. Investigation of seston stoichiometry in the Austrian and Bavarian lakes revealed that with increasing contribution of potentially mixotrophic phytoplankton taxa, seston C:P ratios decreased, as did the variance of $\mathrm{C}: \mathrm{P}$, thus supporting Hypothesis 2.

The 2 lake datasets show systematic deviation in their seston C:P ratio. C:P ratios in the 2 surveys differ most at low \% mixotrophs, while they are very similar towards high \% mixotrophs. A negative relationship between the fraction of mixotrophs and C:P ratio is especially evident in Survey B, while Survey A only shows a decrease in variation of $\mathrm{C}: \mathrm{P}$ ratio with increasing fraction of mixotrophs (Fig. 3). At the same time, the 2 datasets show very similar scaling relationships between total $\mathrm{P}$, algal biovolume and POC (Fig. S3). This confirms that methods for biovolume estimation and sampling procedures are generally comparable. We therefore suggest that the deviation between the 2 surveys reflects different environmental conditions in terms of lakes and climatic conditions (stratification pattern and availability of free resources).

Given the ubiquitous occurrence of mixotrophs in most aquatic environments (Caron 2016), our findings have major implications for trophic transfer and nutrient cycling in plankton food webs. Supporting the initial findings of Katechakis et al. (2005), whose results provided empirical evidence for the hypotheses tested in our study, our findings encompassing a breadth of studies indicate that mixotrophy may indeed enhance the transfer of energy and nutrients to higher trophic levels, ensuring more stable second- 

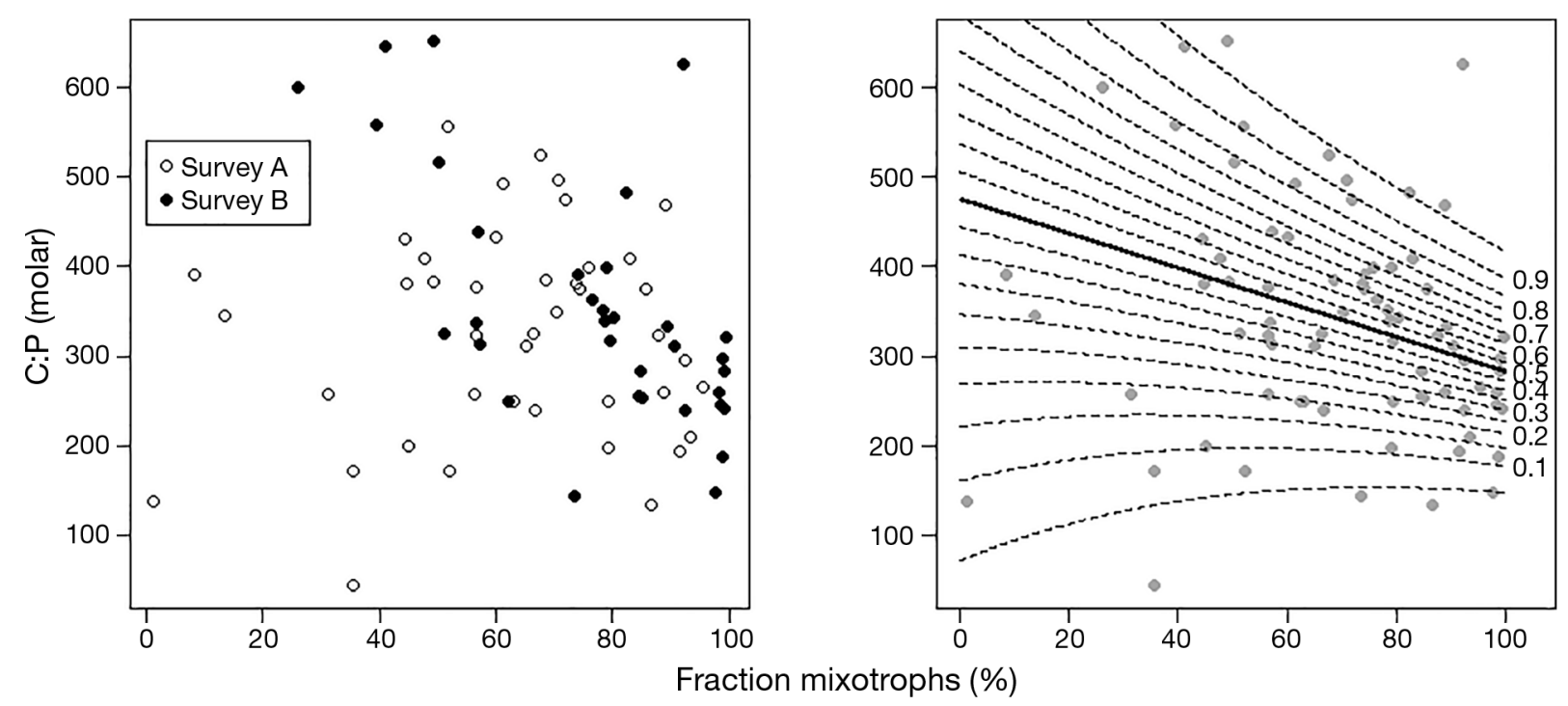

Fig. 3. Sestonic C:P ratio as a function of fraction of mixotrophs in samples from natural lakes. Left panel shows the raw data from 2 surveys: Survey A in 2004 (Striebel et al. 2009a) and Survey B in 2012 (Horváth et al. 2017). The right panel shows all data together with results of analysis using generalized additive models for location scale and shape (GAMLSS), fitting the mean trend to the trend in variation along the $x$-axis. The bold line gives the trend of the mean, dashed lines indicate the percentiles of error variance in steps of $5 \%$ along the predictor (i.e. the area below the lowest line comprises $5 \%$ of the error variance, the next line $10 \%$ etc.). The estimates for the mean $( \pm$ SD) slope and trend in variance are $-1.92 \pm 0.877$ and $-0.011 \pm$ $0.0035, \mathrm{p}=0.003$, respectively, for 76 observations with 72 residual degrees of freedom

ary production in plankton food webs. The large variability in cellular elemental ratios of strict photoautotrophic species can have severe consequences for consumers that generally show a more confined stoichiometry, which can lead to an elemental mismatch of the consumers' nutrient demands and the relatively plastic nutrient balance in their algal prey (e.g. Elser et al. 2000, Persson et al. 2010). Such mismatches alter consumption rates on low quality prey (high C:nutrient), either resulting in prey avoidance, or in compensatory feeding at the consumer individual level (e.g. Hillebrand et al. 2009a). Eventually, feeding on low quality food may lower consumer performance and growth efficiency, leading to reduced consumer population size and trophic transfer (Cross et al. 2003, Fagan \& Denno 2004, Frost et al. 2006, Hillebrand et al. 2009a, Moorthi et al. 2016). Thus, stoichiometric constraints of herbivores may even propagate through the food web to secondary consumers (e.g. Malzahn et al. 2007) and have farreaching consequences for the community structure and productivity of the entire food web.

Anthropogenic nutrient input into the biosphere has almost doubled in the past decades (Vitousek et al. 1997, Rockström et al. 2009), leading to shifting $\mathrm{N}: \mathrm{P}$ ratios in many freshwater and coastal marine systems. Atmospheric $\mathrm{N}$ deposition has already induced a secondary P limitation (Elser et al. 2009), potentially leading to constraints in energy and nutrient flow through consumer-resource interactions and thus biogeochemical cycling in ecosystems (Cherif \& Loreau 2013, Glibert et al. 2013). The results of the present study indicate that the stoichiometric composition of mixotrophs is less affected by changes in nutrient supply than the stoichiometry of strictly photoautotrophic organisms, based on the mixotrophs' ability to use both particulate and dissolved nutrient sources. Potentially limiting nutrients such as $\mathrm{P}$ are often much more concentrated in the prey organisms of mixotrophs, such as bacteria, compared to the dissolved phase (e.g. Vadstein 2000). Bacteria are known to have relatively low and constrained C:P and C:N ratios (Sterner \& Elser 2002, Makino et al. 2003), enabling bacterivorous mixotrophs to maintain low C:nutrient ratios even when dissolved nutrient concentrations are low, potentially making them a nutrient-rich food source for higher trophic levels in nutrient depleted environments. Mixotrophy may thus enhance the transfer of energy and nutrients to higher trophic levels, resulting in more stable secondary production in plankton food webs, as was demonstrated by Katechakis et al. (2005). In a marine study involving N-limited planktonic assemblages, Ptacnik et al. (2004) found that the presence of the mixotrophic flagellate Chrysochromulina led to increasing seston C:N ratios and enhanced copepod reproduc- 
tion. The results by Ptacnik et al. (2004) show that mixotrophy does not necessarily reduce the $\mathrm{C}$ content of seston biomass. Especially in oligotrophic marine systems, bacteria contain a larger fraction of the total amount of nutrients. Here the net effect of bacterivorous mixotrophs may be an enhancement of phytoplankton biomass at the expense of bacteria, resulting in higher sestonic $\mathrm{C}$ content (see also Thingstad et al. 1996 for ambivalent effects of mixotrophs on phototrophic algae).

Chrzanowski et al. (2010) demonstrated that the mixotrophic flagellate Ochromonas danica was more variable in element stoichiometry (C:N, C:P and N:P) in response to different bacterial resource composition compared to purely heterotrophic flagellates. Taken together, the experimental observations of Chrzanowski et al. (2010), Katechakis et al. (2005) and our study suggest that mixotrophic organisms are intermediate in their homeostatic abilities, being more variable in their stoichiometry compared to strict heterotrophs, but less variable compared to strict photoautotrophs. However, more data and studies on the stoichiometry of heterotrophic and mixotrophic protists are required to verify this assumption. The various nutritional strategies that mixotrophic protists have evolved as well as the variable contribution of the 2 nutritional modes to the overall nutrition of the organism substantially complicate the description of food web structure in aquatic systems. The contribution of mixotrophs to net community production on different trophic levels is difficult to quantify, and its integrated impact on global biogeochemical cycles still remains largely unknown. The prevailing nutritional mode of a mixotrophic species strongly determines its influence on trophic dynamics, regarding grazing control, nutrient uptake and regeneration (e.g. Rothhaupt 1997, Fischer et al. 2016, 2017), and very likely also intracellular stoichiometry.

Here, we presented an effort to resolve the effect of mixotrophic organisms on nutrient stoichiometry in plankton food webs. Our study indicates that mixotrophs might enhance food quality for herbivores by constraining stoichiometric variation in the phytoplankton, resulting in a more stable transfer of nutrients and energy to higher trophic levels. However, further studies are necessary to validate this finding and unravel the relationship of different mixotrophic feeding strategies and their influence on nutrient dynamics across trophic levels. Due to the scarcity of data on the stoichiometry of mixotrophs, we could only include a few mixotrophic species that are frequently used in laboratory experiments, and were not able to distinguish between different groups pur- suing different nutritional strategies, such as primarily phototrophic flagellates capable of phagotrophy and primarily heterotrophic protozoa that have gained photosynthetic capacity through kleptoplastidy or symbiotic algae (Caron 2016). Not much is known about protozoa that have kleptoplastidic or symbiotic associations with microalgae, such as ciliates and many species of Rhizaria (Foraminifera, Acantharea, Radiolaria). Rhizaria are particularly common in tropical and subtropical oceans (Caron 2016) and their importance has been grossly underestimated in the world ocean (de Vargas et al. 2015).

There are a few caveats to our investigation. Some studies in our analysis included potential mixotrophs that are known to ingest bacteria grown in nonaxenic cultures, but in which phagotrophic feeding by mixotrophs was not quantified. We assumed that bacteria were ingested and might have potentially buffered nutrient limitation by dissolved nutrients. Furthermore, the laboratory cultures examined in our study were growing under different environmental conditions, such as different light and temperature conditions. The variability of light conditions used in different studies was higher for mixotrophs than for phototrophs and did not play a role as confounding factor for our observations (Fig. S2). However, there was a broader range of nutrient availability (dissolved N:P) for phototrophs than for mixotrophs, which might have contributed to the increased intracellular N:P variability observed in phototrophs compared to mixotrophs.

Temperature data were not consistently provided for different studies and could therefore not be analyzed, although this factor is known to alter the stoichiometry in algae. With increasing temperature, algal C:nutrient ratios have been shown to increase, either due to enhanced carbon fixation per unit resource (e.g. Moorthi et al. 2016) or due to decreasing intracellular $\mathrm{N}$ and $\mathrm{P}$ concentrations based on enhanced efficiency of RNA (requiring P) and proteins (requiring $\mathrm{N}$ ) in biochemical reactions (Woods et al. 2003). Also, the contribution of photosynthesis and phagotrophy varies with temperature in mixotrophs (Wilken et al. 2013, Princiotta et al. 2016), which presumably also alters intracellular nutrient stoichiometry. Our lake data analysis also needs to be considered with some care, as we included all potentially mixotrophic taxonomic groups, but of course cannot be sure whether the dominant organisms in these groups were employing phagotrophic feeding at the time of sampling. Nevertheless, both lab and field data in our study implicate a significant role of mixotrophic organisms in balancing stoichiometric con- 
straints for herbivorous zooplankton, which so far have been neglected in many empirical and theoretical studies focusing on trophic dynamics and nutrient cycling in plankton food webs. An integrated approach combining targeted empirical studies disentangling the effects of different mixotrophic strategies will substantially improve our understanding of the relevance of mixotrophy for ecological stoichiometry and trophic transfer in plankton food webs.

Acknowledgements. The authors thank the editors Paul del Giorgio, Fereidoun Rassoulzadegan, and Eva Lindström for the invitation to contribute to the SAME 14 special issue (Progress and perspectives in aquatic microbial ecology: Highlights of the SAME 14, Uppsala, Sweden, 2015) and Maren Striebel for providing the lake dataset used in the current study. S.D.M. received funding from the Volkswagen Foundation Grant No. 88646.

\section{LITERATURE CITED}

Ågren GI (2004) The C : N : P stoichiometry of autotrophs theory and observations. Ecol Lett 7:185-191

Bockstahler KR, Coats DW (1993a) Grazing of the mixotrophic dinoflagellate Gymnodinium sanguineum on ciliate populations of Chesapeake Bay. Mar Biol 116:477-487

* Bockstahler KR, Coats DW (1993b) Spatial and temporal aspects of mixotrophy in Chesapeake Bay dinoflagellates. J Eukaryot Microbiol 40:49-60

Brutemark A, Granéli E (2011) Role of mixotrophy and light for growth and survival of the toxic haptophyte Prymnesium parvum. Harmful Algae 10:388-394

Burkholder JM, Glibert PM, Skelton HM (2008) Mixotrophy, a major mode of nutrition for harmful algal species in eutrophic waters. Harmful Algae 8:77-93

Caron DA (2000) Symbiosis and mixotrophy among pelagic microorganisms. In: Kirchman DL (ed) Microbial ecology of the oceans. Wiley-Liss, New York, NY, p 495-523

Caron DA (2016) Mixotrophy stirs up our understanding of marine food webs. Proc Natl Acad Sci USA 113: 2806-2808

* Caron DA, Sanders RW, Lim EL, Marrase C and others (1993) Light-dependent phagotrophy in the freshwater mixotrophic chrysophyte Dinobryon cylindricum. Microb Ecol 25:93-111

* Carvalho WF, Granéli E (2010) Contribution of phagotrophy versus autotrophy to Prymnesium parvum growth under nitrogen and phosphorus sufficiency and deficiency. Harmful Algae 9:105-115

Cherif M, Loreau M (2013) Plant-herbivore-decomposer stoichiometric mismatches and nutrient cycling in ecosystems. Proc R Soc B 280:20122453

Chrzanowski TH, Lukomski NC, Grover JP (2010) Element stoichiometry of a mixotrophic protist grown under varying resource conditions. J Eukaryot Microbiol 57: 322-327

* Cross WF, Benstead JP, Rosemond AD, Bruce Wallace J (2003) Consumer-resource stoichiometry in detritusbased streams. Ecol Lett 6:721-732

Daufresne T, Loreau M (2001) Plant-herbivore interactions and ecological stoichiometry: when do herbivores deter- mine plant nutrient limitation? Ecol Lett 4:196-206

* de Vargas C, Audic S, Henry N, Decelle J and others (2015) Eukaryotic plankton diversity in the sunlit ocean. Science 348:1261605

* Elser JJ, Sterner RW, Gorokhova E, Fagan WF and others (2000) Biological stoichiometry from genes to ecosystems. Ecol Lett 3:540-550

Elser JJ, Andersen T, Baron JS, Bergström AK and others (2009) Shifts in lake N:P stoichiometry and nutrient limitation driven by atmospheric nitrogen deposition. Science 326:835-837

F Fagan WF, Denno RF (2004) Stoichiometry of actual vs. potential predator-prey interactions: insights into nitrogen limitation for arthropod predators. Ecol Lett 7: 876-883

Fischer R, Giebel HA, Hillebrand H, Ptacnik R (2016) Importance of mixotrophic bacterivory can be predicted by light and loss rates. Oikos 126:713-722

Fischer R, Giebel HA, Ptacnik R (2017) Identity of the limiting nutrient ( $\mathrm{N}$ vs. P) affects the competitive success of mixotrophs. Mar Ecol Prog Ser 563:51-63

Frost PC, Benstead JP, Cross WF, Hillebrand H, Larson JH, Xenopoulos MA, Yoshida T (2006) Threshold elemental ratios of carbon and phosphorus in aquatic consumers. Ecol Lett 9:774-779

* Gisselson LÅ, Granéli E, Pallon J (2001) Variation in cellular nutrient status within a population of Dinophysis norvegica (Dinophyceae) growing in situ: single-cell elemental analysis by use of a nuclear microprobe. Limnol Oceanogr 46:2137-1242

* Glibert PM, Kana TM, Brown K (2013) From limitation to excess: the consequences of substrate excess and stoichiometry for phytoplankton physiology, trophodynamics and biogeochemistry, and the implications for modeling. J Mar Syst 125:14-28

Hall SR (2004) Stoichiometrically explicit competition between grazers: species replacement, coexistence, and priority effects along resource supply gradients. Am Nat 164:157-172

* Hartmann M, Grob C, Tarran GA, Martin AP, Burkill PH, Scanlan DJ, Zubkov MV (2012) Mixotrophic basis of Atlantic oligotrophic ecosystems. Proc Natl Acad Sci USA 109:5756-5760

Hillebrand H, Borer ET, Bracken ME, Cardinale BJ and others (2009a) Herbivore metabolism and stoichiometry each constrain herbivory at different organizational scales across ecosystems. Ecol Lett 12:516-527

* Hillebrand H, Gamfeldt L, Jonsson PR, Matthiessen B (2009b) Consumer diversity indirectly changes prey nutrient content. Mar Ecol Prog Ser 380:33-41

Killebrand H, Steinert G, Boersma M, Malzahn A, Meunier CL, Plum C, Ptacnik R (2013) Goldman revisited: faster growing phytoplankton has lower $\mathrm{N}: \mathrm{P}$ and lower stoichiometric flexibility. Limnol Oceanogr 58:2076-2088

Horváth Z, Vad CF, Preiler C, Birtel J, Matthews B, Ptáčníková R, Ptacnik R (2017) Zooplankton communities and Bythotrephes longimanus in lakes of the montane region of the northern Alps. Inland Waters 7:3-13

Iwabuchi T, Urabe J (2012) Food quality and food threshold: implications of food stoichiometry to competitive ability of herbivore plankton. Ecosphere 3:51

Jeong HJ, Yoo YD, Kim JS, Seong KA, Kang NS, Kim TH (2010) Growth, feeding and ecological roles of the mixotrophic and heterotrophic dinoflagellates in marine planktonic food webs. Ocean Sci J 45:65-91 
John EH, Flynn KJ (2000) Growth dynamics and toxicity of Alexandrium fundyense (Dinophyceae): the effect of changing $\mathrm{N}$ :P supply ratios on internal toxin and nutrient levels. Eur J Phycol 35:11-23

Johnsen G, Dalløkken R, Eikrem W, Legrand C, Aure J, Skjoldal HR (1999) Eco-physiology, bio-optics and toxicity of the ichthyotoxic Chrysochromulina leadbeateri (Prymnesiophyceae). J Phycol 35:1465-1476

Johnson MD (2015) Inducible mixotrophy in the dinoflagellate Prorocentrum minimum. J Eukaryot Microbiol 62: 431-443

Jones RI (2000) Mixotrophy in planktonic protists: an overview. Freshw Biol 45:219-226

Katechakis A, Haseneder T, Kling R, Stibor H (2005) Mixotrophic versus photoautotrophic specialist algae as food for zooplankton: The light:nutrient hypothesis might not hold for mixotrophs. Limnol Oceanogr 50:1290-1299

Li A, Stoecker DK, Coats DW (2000) Mixotrophy in Gyrodinium galatheanum (Dinophyceae): grazing responses to light intensity and inorganic nutrients. J Phycol 36: 33-45

* Loladze I, Kuang Y, Elser JJ, Fagan WF (2004) Competition and stoichiometry: coexistence of two predators on one prey. Theor Popul Biol 65:1-15

Makino W, Cotner JB, Sterner RW, Elser JJ (2003) Are bacteria more like plants or animals? Growth rate and resource dependence of bacterial C : N : P stoichiometry. Funct Ecol 17:121-130

Malzahn AM, Aberle N, Clemmesen C, Boersma M (2007) Nutrient limitation of primary producers affects planktivorous fish condition. Limnol Oceanogr 52:2062-2071

* Maranger R, Bird DF, Price NM (1998) Iron aquisition by photosynthetic marine phytoplankton from ingested bacteria. Nature 396:248-251

* Mitra A, Flynn KJ, Burkholder JM, Berge T and others (2014) The role of mixotrophic protists in the biological carbon pump. Biogeosciences 11:995-1005

Mitra A, Flynn KJ, Tillmann U, Raven JA and others (2016) Defining planktonic protist functional groups on mechanisms for energy and nutrient acquisition: Incorporation of diverse mixotrophic strategies. Protist 167:106-120

Moorthi SD, Schmitt JA, Ryabov A, Tsakalakis I and others (2016) Unifying ecological stoichiometry and metabolic theory to predict production and trophic transfer in a marine planktonic food web. Philos T R Soc B 371:20150270

Pérez Blanco E, Karlsson C, Pallon J, Yasumoto T, Granéli E (2015) Cellular nutrient content measured with the nuclear microprobe and toxins produced by Dinophysis norvegica (Dinophyceae) from the Trondheim fjord (Norway). Aquat Microb Ecol 75:259-269

* Persson J, Fink P, Goto A, Hood JM, Jonas J, Kato S (2010) To be or not to be what you eat: regulation of stoichiometric homeostasis among autotrophs and heterotrophs. Oikos 119:741-751

Princiotta SD, Smith BT, Sanders RW (2016) Temperaturedependent phagotrophy and phototrophy in a mixotrophic chrysophyte. J Phycol 52:432-440

Ptacnik R, Sommer U, Hansen T, Martens V (2004) Effects of microzooplankton and mixotrophy in an experimental planktonic food web. Limnol Oceanogr 49:1435-1445

Raven JA (1997) Phagotrophy in phototrophs. Limnol Oceanogr 42:198-205

Rigby RA, Stasinopoulos DM (2005) Generalized additive models for location, scale and shape. J R Stat Soc Ser C Appl Stat 54:507-554
Rockström J, Steffen W, Noone K, Persson A and others (2009) A safe operating space for humanity. Nature 461: $472-475$

Kothhaupt KO (1997) Nutrient turnover by freshwater bacterivorous flagellates: differences between a heterotrophic and a mixotrophic chrysophyte. Aquat Microb Ecol 12:65-70

Sanders RW (1991) Mixotrophic protists in marine and freshwater ecosystems. J Protozool 38:76-81

* Sanders RW, Porter KG (1988) Phagotrophic phytoflagellates. Adv Microb Ecol 10:167-192

* Sanders RW, Porter KG, Caron DA (1990) Relationship between phototrophy and phagotrophy in the mixotrophic chrysophyte Poterioochromonas malhamensis. Microb Ecol 19:97-109

* Simonds S, Grover JP, Chrzanowski TH (2010) Element content of Ochromonas danica: a replicated chemostat study controlling the growth rate and temperature. FEMS Microbiol Ecol 74:346-352

* Skovgaard A, Hansen PJ, Stoecker DK (2000) Physiology of the mixotrophic dinoflagellate Fragilidium subglobosum. I. Effects of phagotrophy and irradiance on photosynthesis and carbon content. Mar Ecol Prog Ser 201:129-136

Skovgaard A, Legrand C, Hansen PJ, Granéli E (2003) Effects of nutrient limitation on food uptake in the toxic haptophyte Prymnesium parvum. Aquat Microb Ecol 31: 259-265

Smalley GW, Coats DW (2002) Ecology of the red-tide dinoflagellate Ceratium furca: distribution, mixotrophy, and grazing impact on ciliate populations of Chesapeake Bay. J Eukaryot Microbiol 49:63-73

* Smalley GW, Coats DW, Stoecker DK (2003) Feeding in the mixotrophic dinoflagellate Ceratium furca is influenced by intracellular nutrient concentrations. Mar Ecol Prog Ser 262:137-151

Sterner RW, Elser JJ (2002) Ecological stoichiometry: the biology of elements from molecules to the biosphere. Princeton University Press, Princeton, NJ

Sterner RW, Elser JJ, Fee EJ, Guildford SJ, Chrzanowski TH (1997) The light:nutrient ratio in lakes: the balance of energy and materials affects ecosystem structure and process. Am Nat 150:663-684

* Stickney HL, Hood RR, Stoecker DK (2000) The impact of mixotrophy on planktonoc marine ecosystems. Ecol Modell 125:203-230

* Striebel M, Behl S, Diehl S, Stibor H (2009a) Spectral niche complementarity and carbon dynamics in pelagic ecosystems. Am Nat 174:141-147

Striebel M, Behl S, Stibor H (2009b) The coupling of biodiversity and productivity in phytoplankton communities: consequences for biomass stoichiometry. Ecology 90:2025-2031

* Thingstad TF, Havskum H, Garde K, Riemann B (1996) On the strategy of 'eating your competitor': a mathematical analysis of algal mixotrophy. Ecology 77:2108-2118

* Unrein F, Massana R, Alonso-Sáez L, Gasol JM (2007) Significant year-round effect of small mixotrophic flagellates on bacterioplankton in an oligotrophic coastal system. Limnol Oceanogr 52:456-469

* Unrein F, Gasol JM, Not F, Forn I, Massana R (2014) Mixotrophic haptophytes are key bacterial grazers in oligotrophic coastal waters. ISME J 8:164-176

Vadstein O (2000) Heterotrophic, planktonic bacteria and cycling of phosphorus. In: Schink B (ed) Advances in microbial ecology. Springer, Boston, MA, p 115-167 
Van de Waal DB, Tillmann U, Zhu M, Koch BP, Rost B, John U (2013) Nutrient pulse induces dynamic changes in cellular $\mathrm{C}: \mathrm{N}: \mathrm{P}$, amino acids, and paralytic shellfish poisoning toxins in Alexandrium tamarense. Mar Ecol Prog Ser 493:57-69

Vitousek PM, Aber JD, Howarth RW, Likens GE and others (1997) Human alteration of the global nitrogen cycle: sources and consequences. Ecol Appl 7:737-750

Ward BA, Follows MJ (2016) Marine mixotrophy increases trophic transfer efficiency, mean organism size, and vertical carbon flux. Proc Natl Acad Sci USA 113: 2958-2963

Wilken S, Huisman J, Naus-Wiezer S, Van Donk E (2013)

Editorial responsibility: Paul del Giorgio,

Montreal, Quebec, Canada
Mixotrophic organisms become more heterotrophic with rising temperature. Ecol Lett 16:225-233

*Wilken S, Verspagen JMH, Naus-Wiezer S, Van Donk E, Huisman J (2014) Biological control of toxic cyanobacteria by mixotrophic predators: an experimental test of intraguild predation theory. Ecol Appl 24:1235-1249

* Woods H, Makino W, Cotner J, Hobbie S, Harrison J, Acharya K, Elser J (2003) Temperature and the chemical composition of poikilothermic organisms. Funct Ecol 17: $237-245$

Zubkov MV, Tarran GA (2008) High bacterivory by the smallest phytoplankton in the North Atlantic Ocean. Nature 455:224-226

Submitted: August 2, 2016; Accepted: April 14, 2017 Proofs received from author(s): June 4, 2017 